\title{
EFFECTS OF CYCLIC LONGITUDINAL MECHANICAL STRAIN AND DEXAMETHASONE ON OSTEOGENIC DIFFERENTIATION OF HUMAN BONE MARROW STROMAL CELLS
}

\author{
M. Jagodzinski ${ }^{1 *}$, M. Drescher ${ }^{1}$, J. Zeichen ${ }^{1}$, S. Hankemeier ${ }^{1}$, C. Krettek ${ }^{1}$, U. Bosch $^{2}$ and M. van Griensven \\ ${ }^{1}$ Department of Trauma Surgery, Hanover Medical School (MHH), \\ ${ }^{2}$ Center of Orthopedics and Sports Traumatology, INI, Hanover, Germany
}

\begin{abstract}
The aim of the study was to investigate the effect of cyclic mechanical strain on differentiation markers in the presence or absence of dexamethasone.

Human bone marrow stromal cells (BMSC) from seven donors (32.5 \pm 6.2 years) were cultivated with $\left(\mathrm{D}^{+}\right)$or without (D-) dexamethasone. A cyclic mechanical strain with an elongation of $2 \%(\mathrm{D}+2$; D-2) or $8 \%(\mathrm{D}+8$; D-8) was applied for three days with a stimulation time of three times two hours each day. Levels of alkaline phosphatase (ALP) and osteocalcin (OC) were compared after time intervals of four and seven days. mRNA expression of Collagen I, III and Cbfa1 was investigated after one, four, and seven days.

ALP levels were significantly increased in the $\mathrm{D}+8$ group after four and seven days $(147.1 \pm 6.3 \% ; \mathrm{p}<0.05$ and $168.6 \pm 6,5 \% ; \mathrm{p}<0.03)$ and in the D-8 group after 7 days $(197.4 \pm 10.4 ; p<0.04)$. Cyclic strain had a significant influence on ALP-secretion $(\mathrm{F}=7.5 ; \mathrm{p}<0.01)$.

In the D-8 group there was a significant increase in $\mathrm{OC}$ secretion after 4 days $(140.9 \pm 12.5 \%$; $\mathrm{p}<0.05)$.; $\mathrm{p}<0.01)$. The effect of stretching was significantly stronger than that of dexamethasone ( $\mathrm{F}=17.2$ vs. 1.8). Collagen I ( $\mathrm{Col} \mathrm{I})$ expression was upregulated in $\mathrm{D}+8$ cultures after 4 days $(215.0 \pm 53.3 \mathrm{p}<0.04)$ and after seven days $(166.7 \pm 55.7$; $\mathrm{p}<0.04)$. Collagen III ( $\mathrm{Col}$ III) expression was upregulated in $\mathrm{D}+2$ and $\mathrm{D}+8$ cultures after 4 days $(200.7 \pm 16.3$ and $185.9 \pm 12.7 ; p<0.04)$ and after seven days $(154.4 \pm 10.1$ and $118.8 \pm 16.4 ; p<0.04)$. There was a significant increase of Cbfa1 expression in $\mathrm{D}+8$ cultures at all investigated time intervals (day 1: $105.5 \pm 3.7 \%$; day $4: 104.7 \pm 3.0 \%$; day 7 : $104.4 \pm 2.1 \% ; \mathrm{p}<0.03)$. Stretching $(\mathrm{F}=20.0 ; \mathrm{p}<0.01)$ was a stronger contributor to Cbfa-1 expression than dexamethasone $(\mathrm{F}=12.1 ; \mathrm{p}<0.01)$

Cyclical mechanical stimulation with $8 \%$ elongation increases ALP and OC levels and upregulates Col I and III synthesis and $\mathrm{Cbfa} 1$ expression. In the short term, cyclical stretching is a stronger differentiation factor than dexamethasone. Cyclical stretching and dexamethasone both enhance the osteogenic commitment of hBMSC.
\end{abstract}

Key words: Bone marrow stretching stimulation stress

*Address for correspondence:

Michael Jagodzinski

Department of Trauma Surgery,

Hanover Medical School (MHH),

Carl-Neuberg-Str. 1, 30625 Hanover, Germany

Telephone Number: +49 5115322050

Fax Number: +49 9415325877

E-mail: Jagodzinski.Michael@mh-hannover.de

\section{Introduction}

Large bone defects occur as a result of trauma, infection, tumors or removal of orthopaedic implants. Treatment options include the application of synthetic or biologic substitutes. Obtaining autologous bone from the iliac crest is the gold standard procedure for many orthopaedic procedures. However, this technique is connected with donor site morbidity of more than $30 \%$ (Heary et al., 2002). In the future, tissue engineering techniques may allow bone reconstruction using autologous osteogenic cells.

Human bone marrow stromal cells (hBMSC) are a premier resource for tissue engineering of bone. BMSC can be obtained from different locations and amplified in vitro. Thus, the number of cells available can be increased 100 of times and more (Caplan and Bruder, 2001). The cells can be frozen and thawed without loosing their ability to proliferate and differentiate into bone (Lennon et al., 2001), cartilage (Angele et al., 2003), and fibrous tissue (Altman et al., 2002), which is enhanced by individual cell cultivation protocols. Osteogenic differentiation of hBMSC has been supported by dexamethasone (Byers et al., 1999). Mechanical stress has been demonstrated to stimulate the secretion of osteogenic proteins (Kaspar et al., 2000). Cyclic mechanical stretching modulated the secretion pattern of growth factors in human tendon fibroblasts (Zeichen et al., 2000). Altman and coworkers have shown an increase in fibroblast differentiation of BMSC in a collagen gel matrix when stimulated by cyclic stretching (Altman et al., 2002). There have been several investigations dedicated to examine the influence of cyclic mechanical stretching upon osteoblasts obtained from cancellous bone chips (Kaspar et al., 2000; Neidlinger-Wilke et al., 2001). It could be demonstrated that cyclic stretching stimulates osteoblast proliferation and CICP (procollagen I propeptide) production but decreased the synthesis of alkaline phosphatase and osteocalcin (Kaspar et al., 2000). The magnitude of axial stretching that is necessary in order for cells to respond is lower for fibroblasts than it is for osteocytes (Neidlinger-Wilke et al., 2001). So far, the response of a two dimensional hBMSC culture to cyclic mechanical stretching has not been investigated. Hence, the purpose of the present study was to study the effects of both dexamethasone and cyclic mechanical stretching upon differentiation of hBMSC. 


\section{Methods}

\section{Cell stretching system}

We used a cell stretching system previously described for the stimulation of human fibroblasts (Zeichen et al., 2000). The system consists of rectangular, elastic silicone dishes that are deformable. The apparatus is driven by an eccentric motor that allows variation in the magnitude of stimulation (Fig. 1). The dishes were sterilized by heat and conditioned seven days in Dulbecco's Modified Eagle Medium (DMEM) containing 10\% of human serum, penicillin $(100 \mathrm{U} / 1)$ and streptomycin $(100 \mathrm{mg} / \mathrm{ml})$ at $37^{\circ} \mathrm{C}$ before the cells were plated.

\section{Cell culture conditions}

Human bone marrow aspirates from 7 donors were obtained during routine orthopaedic surgical procedures involving exposure of the iliac crest, after informed consent.

The age of the donors averaged $32.5 \pm 6.2$ years. The cells were purified using a density gradient solution (Bruder $e t$ al., 1994; Cassiede et al., 1996) and cultured in vitro using a standard medium (Dulbecco's modified Eagle medium (DMEM)/Ham's F-12 1:1 with L-glutamine, 10\% human serum, $5 \mu \mathrm{g} / \mathrm{ml}$ ascorbic acid). Culture dishes were incubated at $37^{\circ} \mathrm{C}$ in a humidified atmosphere of $5 \%$ carbon dioxide and $95 \%$ air. Culture medium was changed after the first four days and thereafter every two days. After cells reached confluence (usually about three to four weeks), they were released with $0.05 \%$ trypsin. For first passage cultures $(\mathrm{P} 1)$, an equal number of cells were plated in flasks with a culture surface of $75 \mathrm{~cm}^{2}$. To obtain enough cells, the BMSCs underwent two other passages (P2, P3). Each time, they were split and grown in an increased number of culture flasks. Starting at the second passage, dishes were divided into 2 different groups: in the first group, $2.55 \mu \mathrm{M}$ dexamethasone was added to the cell culture medium (D+). The second group was cultivated without dexamethasone (D-; Fig. 2). After the second passage, $2.5 \times 10^{5}$ cells were seeded on flexible silicone dishes. After three days of incubation with culture medium to allow cell attachment and spreading, the concentration of human serum was reduced to $1 \%$ for 24 hours to align most cells into the $\mathrm{G}_{0}$ phase of the cell cycle. Previous experiments using cell cycle analysis showed that after 24 hours more than $70 \%$ of the cells were in the $\mathrm{G}_{0}$ phase (Zeichen et al., 2000). During this phase, cells down-regulate the proliferation rate and protein synthesis. Thus, this procedure maximizes potential differences of these parameters.

\section{Cell stretching experiments}

The dishes were divided into six different groups: in

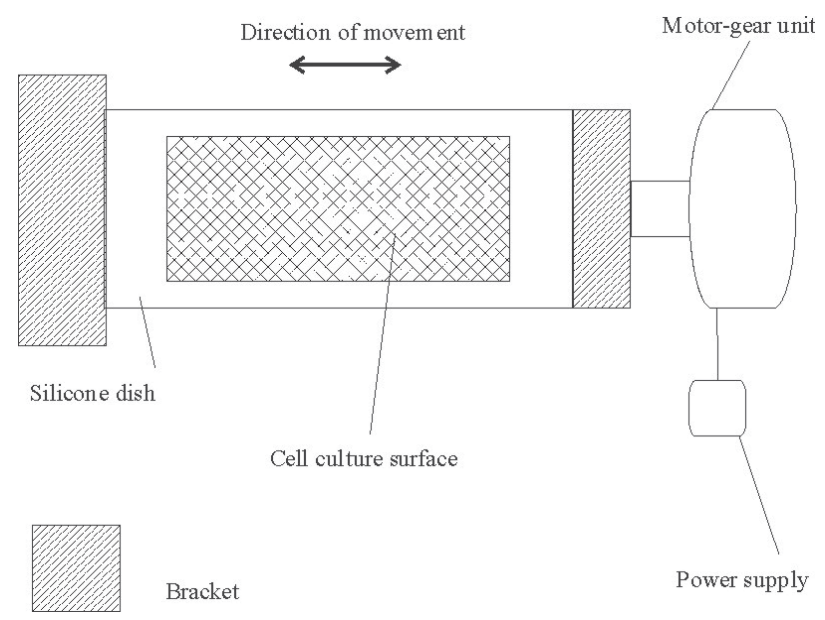

Figure 1. In the cell stretching system, the silicone dishes are fixed at one end and held in a movable clamp at the other end. Mechanical longitudinal stretching of the dishes occurred by motor-driven movements of the clamp back and forth, so the dishes were stretched and relaxed along the longitudinal axis.

groups one through three, $2.55 \mu \mathrm{M}$ dexamethasone was added to the cell culture medium (D+).Groups four to six were cultured without dexamethasone (D-). Four groups were exposed to 3 repetitions of 2 hours of cyclic mechanical stretching and a break of 1 hour (Table 1). The cells of group one and four were subjected to cyclic mechanical strain of $2 \%(\mathrm{D}+2 ; \mathrm{D}-2)$ and groups two and five to $8 \%$ cyclic mechanical strain (D+8; D-8) at a frequency of 1 Hz. A rest of 21 hours was given in between stretching. Groups three and six were cultured without mechanical stimulation as controls (D+0; D-0; Fig. 2). The silicone dishes were incubated at $37^{\circ} \mathrm{C}$ in a humidified atmosphere of $5 \%$ carbon dioxide and $95 \%$ air.

\section{Analysis of alkaline phosphatase and osteocalcin}

Differentiation markers were determined on the first and fourth day following stimulation (d4, d7). At these time intervals, cells were harvested from the dishes and homogenized. The content of protein was determined by the method of Lowry and a photometric detection of levels of alkaline phosphatase (ALP) was conducted. Osteocalcin (OC) levels were investigated using an enzyme linked immuno-sorbent assay kit, that was used according to the guidelines of the manufacturer (N-MID ${ }^{\text {TM }}$ Osteocalcin One Step ELISA, Osteometer BioTech, Herlev, Denmark). The optical density of the probes was measured in an ELISA reader at a wavelength of 450nm. Values of strained cells were divided by values obtained from control dishes in order

\begin{tabular}{|l|l|l|l|l|}
\hline Day 1 & Day 2 & Day 3 & Day 4 & Day7 \\
\hline $\begin{array}{l}3 \times 2 \text { hours cyclic } \\
\text { stimulation at 1Hz- } \\
\text { PCR-samples }\end{array}$ & $\begin{array}{l}3 \times 2 \text { hours cyclic } \\
\text { stimulation at } 1 \mathrm{~Hz}\end{array}$ & $\begin{array}{l}3 \times 2 \text { hours cyclic } \\
\text { stimulation at } 1 \mathrm{~Hz}\end{array}$ & $\begin{array}{l}\text { ALP } \\
\text { OC } \\
\text { PCR-samples }\end{array}$ & $\begin{array}{l}\text { OCP } \\
\text { PCR-samples }\end{array}$ \\
\hline
\end{tabular}

Table 1: Cell stretching and sample collection protocol in this study. 


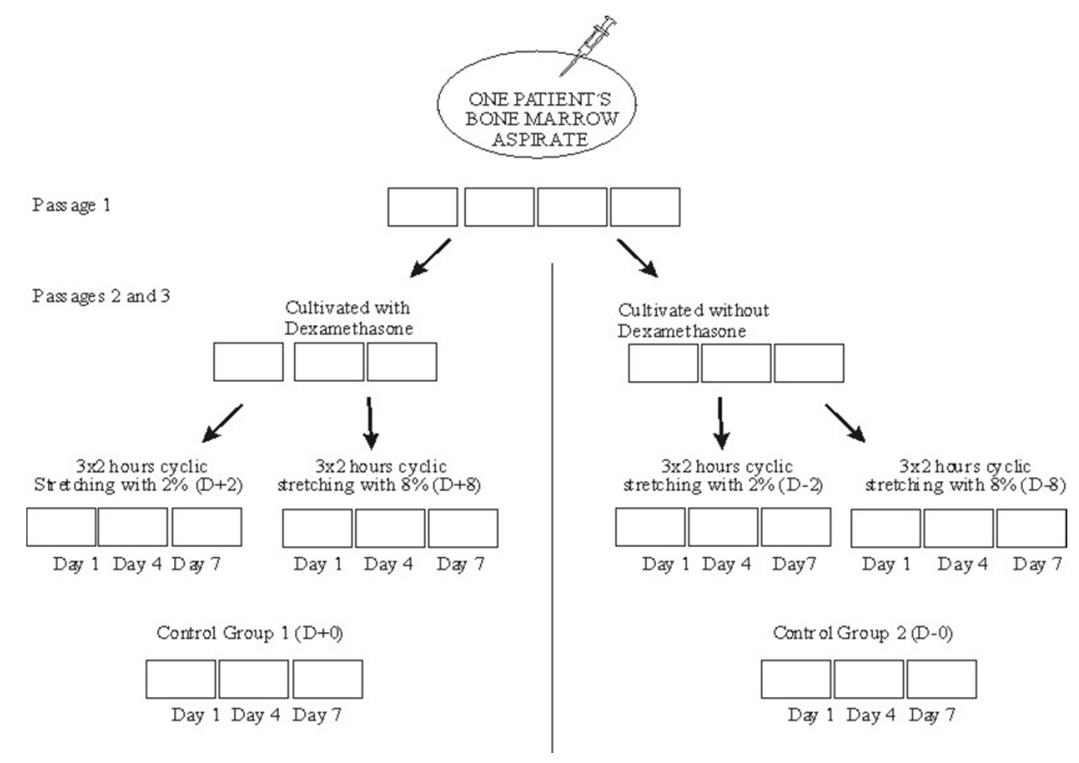

Figure 2. BMSC's from one patient were pooled, purified using a density gradient solution, and cultured in vitro using standard media (Dulbecco's modified Eagle medium (DMEM) / Ham's F-12 1:1 with L-glutamine, 10\% human serum, $5 \mu \mathrm{g} / \mathrm{ml}$ ascorbic acid and 100U/1 penicillin/ streptomycin). In order to provide enough cells, BMSC underwent three passages. After the first passage, in half the cell culture flasks, $2.55 \mu \mathrm{M}$ dexamethasone was added to the culture medium. Cells of the third passage were plated on eighteen silicone dishes $\left(2.5 \times 10^{5}\right.$ cells/ silicone dish $)$. Twelve silicone dishes were divided into four groups: $2 \%$ and $8 \%$ cyclic strain with (D+) or without (D-) dexamethasone for three times two hours on three subsequent days. The other six silicone dishes were used for controls. Cells were tested for differentiation parameters the first day immediately after stretching, the fourth and seventh day following the beginning of the experiment.

to compare the effects of the various strains and dexamethasone on cellular proliferation and differentiation.

\section{Quantitative reverse transcriptase polymerase chain reaction}

We extracted DNA using Trizol according to the singlestep acid-phenol guanidinium method (Chornczynsky and Sacchi, 1987). cDNA synthesis was performed using Superscript II RNAse $\mathrm{H}^{-}$Reverse Transcriptase (Invitrogen $\mathrm{GmbH}$, Karlsruhe, Germany) and a Taq DNA Polymerase Kit ${ }^{\mathrm{TM}}$ (Qiagen, Valencia, CA, USA). We monitored RT-PCR reactions using a GeneAmp ${ }^{\circledR}$ PCR System 9700 (Perkin Elmer, Norwalk, CT, USA), with settings as as follows: For cDNA, we used four holds $\left(5 \mathrm{~min}\right.$ at $94^{\circ} \mathrm{C}, 10 \mathrm{~min}$ at $4^{\circ} \mathrm{C}, 60 \mathrm{sec}$ at $37^{\circ} \mathrm{C}$, and $5 \mathrm{~min}$ at $90^{\circ} \mathrm{C}$ ). For GAPDH, we used two holds $\left(5 \mathrm{~min}\right.$ at $94^{\circ} \mathrm{C}, 7 \mathrm{~min}$ at $\left.72^{\circ} \mathrm{C}\right)$ and thirty-three cycles $(45 \mathrm{sec}$ at $94^{\circ} \mathrm{C}, 45 \mathrm{sec}$ at $60^{\circ} \mathrm{C}$, and $45 \mathrm{sec}$ at $72^{\circ} \mathrm{C}$ ). For Collagen III, we used two holds $\left(5 \mathrm{~min}\right.$ at $94^{\circ} \mathrm{C}, 7 \mathrm{~min}$ at $\left.72^{\circ} \mathrm{C}\right)$ and forty cycles $\left(45 \mathrm{sec}\right.$ at $94^{\circ} \mathrm{C}, 45 \mathrm{sec}$ at $58^{\circ} \mathrm{C}$, and $45 \mathrm{sec}$ at $\left.72^{\circ} \mathrm{C}\right)$. For Tenascin-C and Cbfa- 1 , two holds $\left(5 \mathrm{~min}\right.$ at $94^{\circ} \mathrm{C}$, $7 \mathrm{~min}$ at $\left.72^{\circ} \mathrm{C}\right)$ and thirty-five cycles $\left(45 \mathrm{sec}\right.$ at $94^{\circ} \mathrm{C}, 45 \mathrm{sec}$ at $58^{\circ} \mathrm{C}$, and $45 \mathrm{sec}$ at $72^{\circ} \mathrm{C}$ ) were selected. The level of expression of each target gene was normalized to the reference gene glyceraldehyde phosphate dehydrogenase (GAPDH; (Altman et al., 2002; Byers et al., 1999)) and then expressed as a fraction of the average expression levels measured in samples that were not cyclically stretched. Primers and probes were as follows: GAPDH: sense: ACCACAGTCCATGCCATCAC; antisense: TCCACCACCCTGTTGCTGTA, collagen III: sense: CAGGTGAACGTGGAGCTGC; antisense: TGCCACCAGTGTTTCCGTGG. Cbfa1: sense:
GAGTGGACGAGGCAAGAG; antisense: GGGTGGTAGAGTGGATGG; the primers for collagen I and tenascin-C have been described previously (Altman et al., 2002).

\section{Statistical analysis}

The data from 7 experiments were statistically evaluated. Absolute values were transferred into relative changes of each parameter dividing the values of stretched samples by the values of unstretched controls (the baselines represent an expression of $100 \%$ of the controls). The figures represent the 4 different combinations of stretching and dexamethasone at 2 (3) different time intervals. Results are reported by mean and standard deviation. To study pairs of dependent variables (stretched vs. control), we used a non parametric two-tailed WilcoxonTest. A general linear model for repeated measures analysis of variance with an F-test for between-subject contrasts were used to study the influence of factors on cell differentiation. The F-value is a parameter that allows comparing the strength of the effects of various potential factors. Between-subjects effects were further analyzed using a post-hoc Tukey-Kramer test (SPSS 10.0, SPSS Inc., Chicago, IL, USA). The level of significance was predetermined at a p-value of 0.05 . 


\section{Results}

\section{ALP}

Comparison of ALP levels revealed that cells subjected to cyclic stimulation at $8 \%$ expressed significantly more ALP than unstretched controls when cultured with dexamethasone after 4 and 7 days $(147.1 \pm 6,3 \%$; $<<0.05$ and $168.6 \pm 6,5 \% ; \mathrm{p}<0.03)$ and without dexamethasone after 7 days (197.4 $\pm 10.4 ; p<0.04$; Fig. 3$) .8 \%$ cyclical stretching enhanced ALP levels more than $2 \%$ stretching $(\mathrm{p}<0.01)$. Analysis of the between-subject effects showed that stretching had a significant influence on ALP-secretion ( $\mathrm{F}=7.5$; $\mathrm{p}<0.01)$. This effect was thirteen times stronger than that of dexamethasone $(\mathrm{F}=0.6)$. There were no significant differences between cell cultures treated with dexamethasone compared with those cultivated without dexamethasone.

\section{Osteocalcin}

Overall, there was little expression of osteocalcin which is represented by the high standard deviation of relative OC levels. Only cells cultured without dexamethasone and stimulated with $8 \%$ cyclical stretching showed a significant increase compared with controls after 4 days $(140.9 \pm 12.5 \% ; \mathrm{p}<0.05)$. These samples contained significantly more osteocalcin compared with the cells exposed to $2 \%$ stretching $(\mathrm{D}+2$ : $108.8 \pm 13.5$; D-2: $115.2 \pm 13.0$; $\mathrm{p}=0.04$; Fig. 4).

There was a significant effect of cyclical stretching on osteocalcin secretion $(\mathrm{F}=17.2 ; \mathrm{p}<0.01)$. This effect was significantly stronger than that of dexamethasone $(\mathrm{F}=1.8$; $\mathrm{p}<0.01)$. $8 \%$ cyclical stretching increased osteocalcin secretion compared with $2 \%$ and no stimulation after 4 days $(p<0.01)$. There were no significant differences between cell cultures treated with dexamethasone compared with those cultivated without dexamethasone.

\section{Collagen I}

Collagen I (Col I) expression was significantly increased in cell cultures cultivated with dexamethasone and stimulated with $8 \%$ cyclical stretching after 4 days $(215.0 \pm 53.3$; $\mathrm{p}<0.04)$ and after seven days $(166.7 \pm 55.7 ; \mathrm{p}<0.04)$. There was a significant difference between 2 and $8 \%$ cyclical stimulation $(p<0.01)$ and a significant interaction between dexamethasone and stimulation after 4 days $(p<0.01)$. The combination of dexamethasone and cyclical mechanical stimulation had a significant effect on collagen I expression after 7 days $(\mathrm{p}<0.01)$. The effect of cyclical stretching was higher than that of dexamethasone ( $\mathrm{F}=1.7$ vs. 0.7$)$. There were no significant differences between cell cultures treated with dexamethasone compared with those cultivated without dexamethasone. The data for collagen I expression is shown in Figure 5.

\section{Collagen III}

Collagen III (Col III) expression was significantly increased in cell cultures cultivated with dexamethasone and stimulated with $2 \%$ and $8 \%$ cyclical stretching after 4 days $(200.7 \pm 16.3$ and $185.9 \pm 12.7 ; \mathrm{p}<0.04)$ and after seven days $(154.4 \pm 10.1$ and $118.8 \pm 16.4 ; \mathrm{p}<0.04)$. There was a significant difference in collagen III expression between cells exposed to dexamethasone compared with those that were
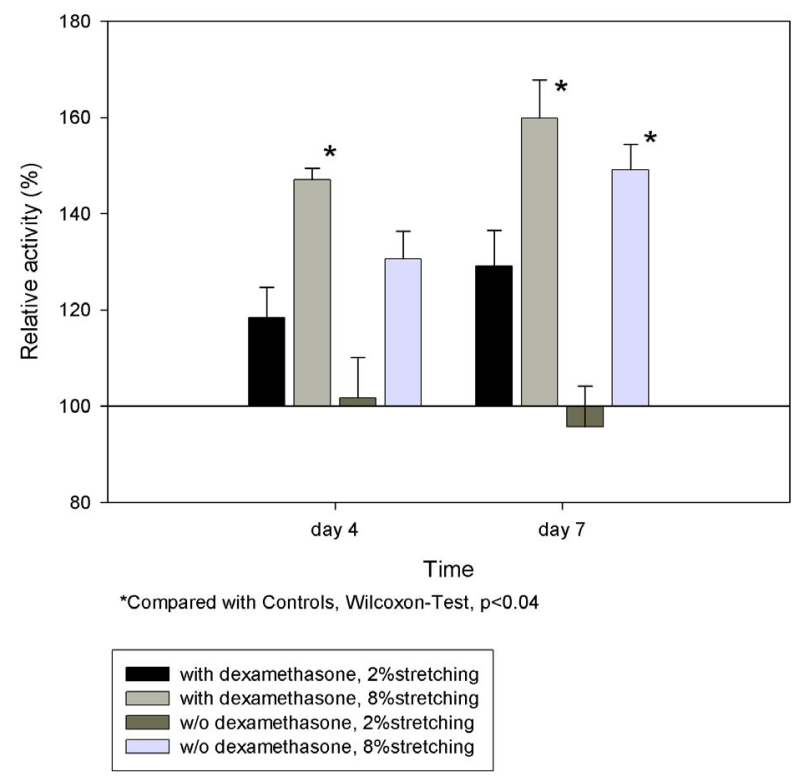

Figure 3. Increase in alkaline phosphatase activity compared with controls that were not mechanically stretched: There was a significant increase in relative activity in cultures strained with $8 \%$ of cyclic stretching and cultivated with dexamethasone after four and seven days and in cell cultures strained with $8 \%$ that did not receive dexamethasone after seven days.

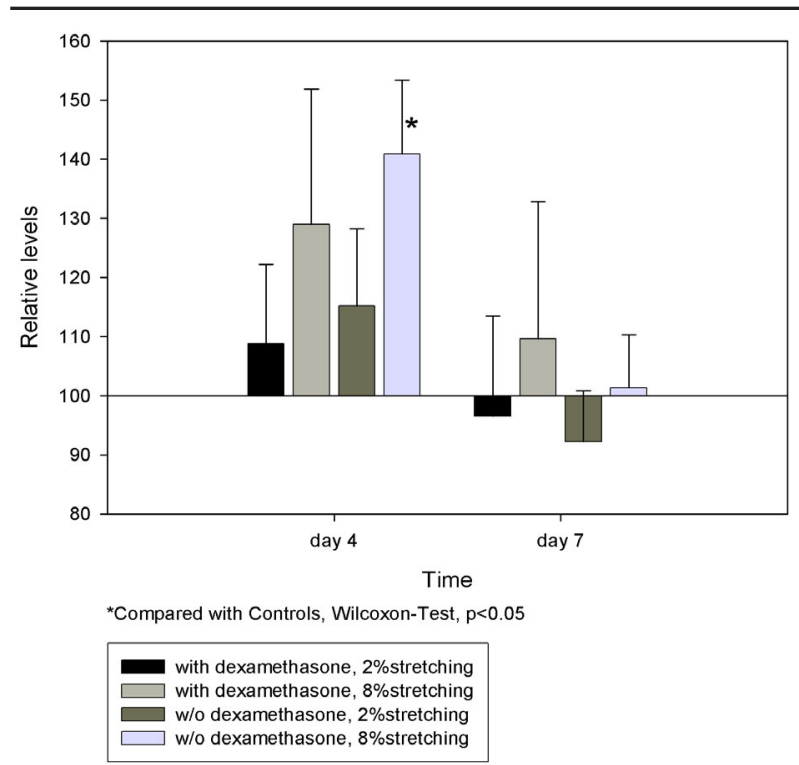

Figure 4. Secretion of osteocalcin compared with controls that were not mechanically stimulated: There was a high variation in response to cyclic stretching; significant increased levels compared with controls that were not cyclically stretched could only be observed in the D-8 group after four days.

treated without dexamethasone after 7 days $(184.6 \pm 58.1 \%$; $\mathrm{p}<0.03)$. Mechanical strain had a stronger effect on Col III expression than dexamethasone ( $\mathrm{F}=11.7$ vs. 0.1 ). The combination of dexamethasone and cyclical mechanical stimulation had a significant effect on Col III expression ( $\mathrm{F}=3.6$; $\mathrm{p}<0.02)$. The data for collagen III expression is shown in Figure 6. 


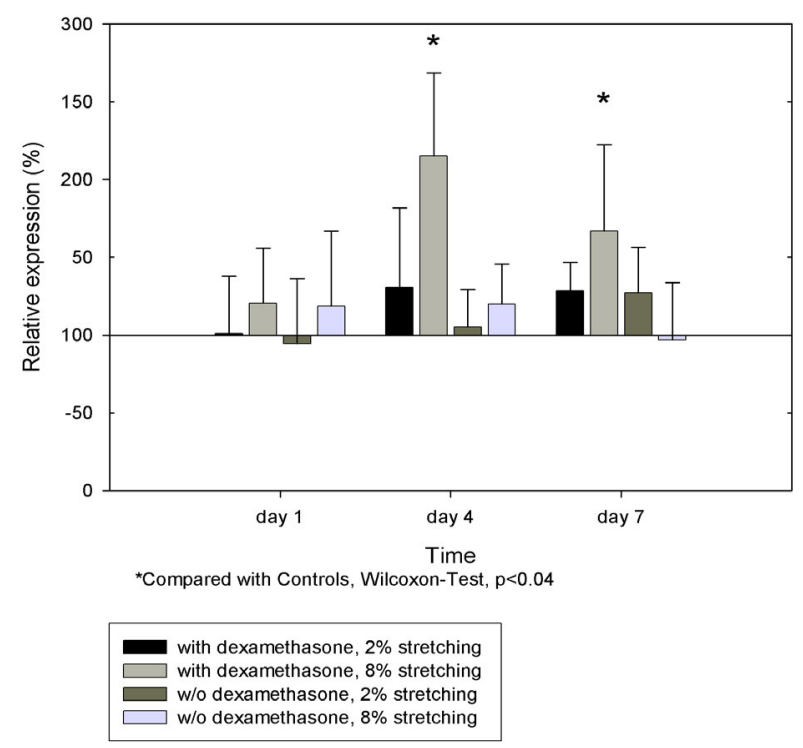

Figure 5. Collagen I mRNA expression: There was an upregulation of collagen I expression in the group treated with dexamethasone and $8 \%$ stimulation after four and seven days. There was a significant difference between 2 and $8 \%$ cyclical stimulation $(\mathrm{p}<0.01)$ and a significant interaction between dexamethasone and stimulation after 4 days $(\mathrm{p}<0.01)$. The combination of dexamethasone and cyclical mechanical stimulation had a significant effect on collagen I expression after 7 days $(\mathrm{p}<0.001)$.

\section{Cbfa1}

We detected a significant increase of Cbfa1 expression of cells exposed to $8 \%$ stretching and dexamethasone at all investigated time intervals compared with unstretched controls (day 1: $105.5 \pm 3.7 \%$; day $4: 104.7 \pm 3.0 \%$; day 7 : $104.4 \pm 2.1 \%$; $<<0.03)$. There was a significant upregulation of Cbfa1 expression of cells exposed to $8 \%$ stretching cultured without dexamethasone after 7 days $(105.3 \pm 3.6 \%$; $\mathrm{p}<0.03$ Fig. 7). There was a time dependent effect of dexamethasone $(\mathrm{F}=4.4 ; \mathrm{p}<0.03)$. Between subject contrasts identified cyclical stretching $(F=20.0 ; p<0.01)$ as a stronger contributor to $\mathrm{Cbfa}-1$ expression than dexamethasone $(\mathrm{F}=12.1 ; \mathrm{p}<0.01) .8 \%$ cyclical stretching had significantly more effect on Cbfa-1 expression than $2 \%$ stretching $(p<0.01)$. There were no significant differences between cell cultures treated with dexamethasone compared with those cultivated without dexamethasone.

\section{Discussion}

This study investigated factors that have been found to affect the secretion of differentiation markers of osteoblasts and BMSC in vitro. $8 \%$ cyclic stretching in silicone-dishes significantly increased ALP-, OC secretion and Col I and Cbfa- 1 expression compared with $2 \%$ and no stimulation. Col III expression was significantly increased following 4 and 7 days after cyclic mechanical stimulation with 2 and $8 \%$ stretching. As the cells were adherent to the silicone surface of the dishes, $2 \%$ stimulation in this study may differ from the stimulation used by other authors (Altman et

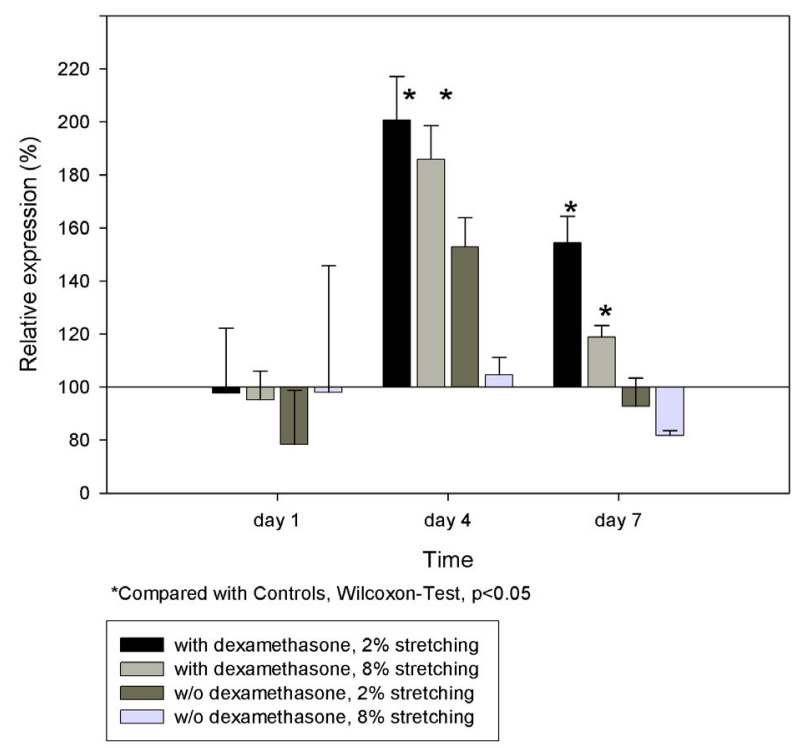

Figure 6. Collagen III mRNA expression: Significant increased expression could be detected for $\mathrm{D}+2$ and $\mathrm{D}+8$ groups after four and seven days.

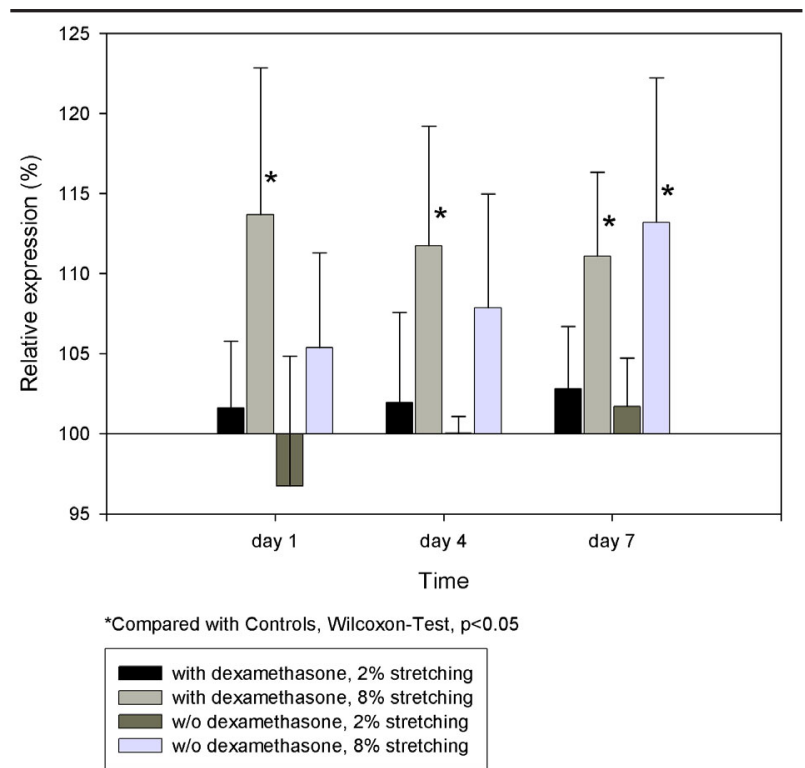

Figure 7. Cbfa 1 mRNA expression: Cultures that were exposed to dexamethasone and $8 \%$ cyclic mechanical stimulation reacted quicker with a significant increase than cultures with the same amount of stretching that were not exposed to dexamethasone (significant increase after seven days, *)

al., 2002) with BMSCs embedded in a collagen matrix. These investigators did not detect an osteogenic differentiation following two weeks of continuous axial and rotational stimulation. The collagen matrix, and the different culture media used (including fibroblast growth factor, FGF), may have lead up to these discrepancies. The results of this study also differ from findings for the stimulation of osteocytes (Kaspar et al., 2000). The stimulation with 1 $\mathrm{Hz}$ and a strain magnitude of 1000 microstrain (1\% stretching) in a two dimensional culture on silicone dishes in a 4point bending device increased the proliferation (10-48\%) and carboxyterminal collagen type I propeptide release (7$49 \%$ ) of human-cancellous bone-derived osteoblasts but 
reduced alkaline phosphatase activity and osteocalcin release by $9-25$ and $5-32 \%$, respectively. We therefore conclude that there are substantial differences between BMSC and osteocytes with respect to their reaction on cyclic strain. Osteocytes dedifferentiate as a response to strain (Kaspar et al., 2000). This behaviour is different from BMSC, which follow, even without osteogenic media, the pathway of osteogenic differentiation, especially as a response to mechanical stimulation.

Dexamethasone has been found to stimulate the secretion of ALP of hBMSC in vitro (Jaiswal et al., 1997). In this study, there was less effect of dexamethasone on cell differentiation compared with cyclical stretching for the observed time interval. However, the significant findings of the above mentioned studies were reported after a time interval of four weeks. After one week, no significant difference could be detected. The results of this investigation demonstrate that stretching is a stronger factor promoting osteogenic differentiation than dexamethasone with short term cyclic mechanical stretching. The combination of cyclic mechanical stretching and dexamethasone increased collagen III-expression of BMSC in vitro significantly.

The results of this study show a discordant response of the main markers of osteogenesis, Cbfa-1, ALP, and OC. Dexamethasone increased the production of Cbfa-1 and ALP (Fig. 3 and Fig. 7), but decreased the production of OC (Fig. 4). However, we detected very little secretion of OC. Thus, this parameter must be interpreted very carefully. The expression of Cbfa- 1 was limited over time, which has been reported previously (Frank et al., 2002).

Neidlinger-Wilke and coworkers have identified a lower axial strain limit for fibroblasts, $(4.2 \pm 0.4 \%)$, than for osteoblasts $(6.4 \pm 0.6 \%)$ (Neidlinger-Wilke et al., 2001). This strain level for osteoblasts corresponds with the findings of this study for BMSC. We observed significant increases of ALP, OC, Col I, Col III, and Cbfal predominantly in the groups that were exposed to $8 \%$ of cyclic stretching.

The major limitation of this study is the heterogeneity of hBMSC with respect to morphology and differentiation. This is consistent with the view that these cells belong to a lineage hierarchy in which only some of the cells are multipotential stem cells or primitive progenitors whereas others are more restricted (Aubin and Triffitt, 2002). This phenomenon explains the high variances found in this study, especially for OC and Cbfa-1 expression.

Cbfa- 1 has been identified as one of the earliest differentiation markers that regulate OC expression (Yamaguchi et al. 2000). Cbfa-1 was found to be upregulated early following $8 \%$ cyclical stretching stimulation in cell cultures that were exposed to dexamethasone. OC was upregulated after four days, which indicates that at least some of the cells were already differentiated into preosteoblastic phenotype (Yamaguchi et al., 2000).

The implications of this study for the application of mechanical stimulation for tissue engineering, are 2-fold: If no other differentiation factor is used, BMSC will respond with a osteogenic differentiation. This can be an undesirable response in protocols aiming for a transformation into the fibroblastic or chondrogenic phenotype. Since the long term fate of BMSCs transferred into the human body is yet not clear, mechanical stimulation that occurs after transplantation of a tissue engineered constructs may cause a calcification of the matrix.

Osteogenic differentiation can be obtained using a number of well investigated differentiation factors, amongst those bone morphogenic proteins (Vehof et al., 2001) and dexamethasone (Jaiswal et al. 1997). Mechanical stimulation is a promising factor that stimulates both differentiation and structural alignment (Neidlinger-Wilke et al., 2001) of BMSCs.

The findings of this study must be interpreted with care due to the small number of cases and the heterogeneity of the individual BMSC cultures.

Further research is necessary to determine the long term effects of cyclic mechanical stretching and to apply cyclic mechanical strain to three-dimensional cell-matrix systems.

\section{Acknowledgements}

We wish to thank L. Hoy, Ph.D., for assistance with the statistical analysis of the data.

\section{References}

Altman GH, Horan RL, Martin I, Farhadi J, Stark PR, Volloch V, Richmond JC, Vunjak-Novakovic G, Kaplan DL (2002) Cell differentiation by mechanical stress. FASEB J 16: $270-272$.

Angele P, Yoo JU, Smith C, Mansour J, Jepsen KJ, Nerlich M, Johnstone B (2003) Cyclic hydrostatic pressure enhances the chondrogenic phenotype of human mesenchymal progenitor cells differentiated in vitro. J Orthop Res 21: 451-457.

Aubin JE, Triffitt JT (2002) Mesenchymal stem cells and osteoblast differentiation. In: Principles of Bone Biology. Bilezikian JP, Raisz LG, Rodan GA (eds). Academic Press, San Diego, pp 59-81.

Bruder SP, Fink DJ, Caplan AI (1994) Mesenchymal stem cells in bone development, bone repair, and skeletal regeneration therapy. J Cell Biochem 56: 283-294.

Byers RJ, Brown J, Brandwood C, Wood P, Staley W, Hainey L, Freemont AJ, Hoyland JA (1999) Osteoblastic differentiation and mRNA analysis of STRO-1-positive human bone marrow stromal cells using primary in vitro culture and poly (A) PCR. J Pathol 187: 374-381.

Caplan AI, Bruder SP (2001) Mesenchymal stem cells: building blocks for molecular medicine in the 21 st century. Trends Mol Med 7: 259-264.

Cassiede P, Dennis JE, Ma F, Caplan AI (1996) Osteochondrogenic potential of marrow mesenchymal progenitor cells exposed to TGF-beta 1 or PDGF-BB as assayed in vivo and in vitro. J Bone Miner Res 11: 12641273.

Chornczynsky P, Sacchi N (1987) Single-step method of RNA isolation by acid guanidinium thiocyanate-phenolchloroform extraction. Anal Biochem 162: 156-159.

Frank O, Heim M, Jakob M, Barbero A, Schafer D, 
Bendik I, Dick W, Heberer M, Martin I (2002) Real-time quantitative RT-PCR analysis of human bone marrow stromal cells during osteogenic differentiation in vitro. J Cell Biochem 85: 737-746.

Heary RF, Schlenk RP, Sacchieri TA, Barone D, Brotea C (2002) Persistent iliac crest donor site pain: independent outcome assessment. Neurosurgery 50: 510-516.

Jaiswal N, Haynesworth SE, Caplan AI, Bruder SP (1997) Osteogenic differentiation of purified, culture-expanded human mesenchymal stem cells in vitro. J Cell Biochem 64: 295-312.

Kaspar D, Seidl W, Neidlinger-Wilke C, Ignatius A, Claes L (2000) Dynamic cell stretching increases human osteoblast proliferation and CICP synthesis but decreases osteocalcin synthesis and alkaline phosphatase activity. J Biomech 33: 45-51.

Lennon DP, Edmison JM, Caplan AI (2001) Cultivation of rat marrow-derived mesenchymal stem cells in reduced oxygen tension: effects on in vitro and in vivo osteochondrogenesis. J Cell Physiol 187: 345-355.

Neidlinger-Wilke C, Grood ES, Wang JHC, Brand RA, Claes L (2001) Cell alignment is induced by cyclic changes in cell length: studies of cells grown in cyclically stretched substrates. J Orthop Res 19: 286-293.

Vehof JW, de Ruijter AE, Spauwen PH, Jansen JA (2001) Influence of rhBMP-2 on rat bone marrow stromal cells cultured on titanium fiber mesh. Tissue Eng 7: $373-$ 383.

Yamaguchi A, Komori T, Suda T (2000) Regulation of osteoblast differentiation mediated by bone morphogenetic proteins, hedgehogs, and Cbfa1. Endocr Rev 21: 393-411.

Zeichen J, van Griensven M, Bosch U (2000) The proliferative response of isolated human tendon fibroblasts to cyclic biaxial mechanical strain. Am J Sports Med 28: 888-892.

\section{Discussion with Reviewers}

I. Martin: What is the physiological relevance of studying cell response to strain using a 2-dimensional model system, where cells are grown on silicone?

Authors: Amplification of human bone marrow stromal cells in a 2-dimensional cell culture is a widespread tool for various tissue engineering applications. Mechanical stimulation has been reported to stimulate the secretion patterns of osteoblasts (Kaspar et al., 2000) and fibroblasts (Skutek et al., 2001). The stimulation mode used in the current study affects differentiation towards the osteogenic lineage. This is an important effect that is helpful for the tissue engineering of bone but is detrimental for the creation of both tendons and cartilage. Cell culture conditions are easier to investigate in a 2-dimensional system than they are in a 3-dimensional system where there is an effect of matrix composition. Cell seeding, and the amount of stretching on the individual cell can not be controlled in the same manner.

I. Martin: Using the highly sensitive real-time quantitative RT-PCR technique, variations of up to one cycle in the amplification curves (corresponding to 2-fold differences in the measured gene expression) can easily occur. Considering this fact, can we consider reliable and relevant differences of $20 \%, 60 \%$ or even $80 \%$ in the expression of a specific gene, if measured by such technique?

Authors: The increases of the differentiation markers reported in this study have to be interpreted with care. Especially the increases in Cbfa-1 expression that were in the range of $3-10 \%$ and thus very slim. However, we observed increased expressions in 6 of our 7 experiments, which corresponds with the narrow standard deviations. The RTPCR technique is more reliable in finding gene expressions of selected markers than it is to compare the amount of expression.

C. Evans: How clinically applicable and economical will be a protocol that requires mechanical stimulation of MSCs for several days? Why not simply add a recombinant growth factor, such as BMP-7?

Authors: Up to the present point, growth factors like BMP7 seem to be a very powerful tool in order to enhance the osteogenic differentiation of BMSC. Histological evaluation of in vivo application has shown, however, that the 3dimensional structure of bone that has been formed under the stimulation of BMP-2 is inferior to native bone and that osteoclasts are also stimulated, which lead up to cystic formations within the regenerate. Mechanical stimulation may be a tool that not only supports osteogenic differentiation, but also improves the 3-dimensional properties of bone using tissue engineering techniques. For the application of cyclic compression/ stretching, new mechanoreactors have to be designed that enable a clinically applicable and economical way of using these stimulation techniques.

\section{Additional Reference}

Skutek M, van Griensven M, Zeichen J, Brauer N, Bosch U (2001) Cyclic mechanical stretching enhances secretion of Interleukin 6 in human tendon fibroblasts. Knee Surg Sports Traumatol Arthrosc 9: 322-326. 